\title{
Distress correlates with the degree of chest pain: a description of patients awaiting revascularisation
}

\author{
Ann Bengtson, Johan Herlitz, Thomas Karlsson, Åke Hjalmarson
}

\begin{abstract}
Aim-To describe various symptoms other than pain among consecutive patients on the waiting list for possible coronary revascularisation in relation to estimated severity of chest pain.

Design-All patients were sent a postal questionnaire for symptom evaluation.

Subjects-All patients in western Sweden on the waiting list in September 1990 who had been referred for coronary angiography or coronary revascularisation $(n=$ 904).

Results $-88 \%$ of the patients reported chest pain symptoms that limited their daily activities to a greater or lesser degree. Various psychological symptoms including anxiety and depression were strongly associated with the severity of pain $(P<0.001)$, as were sleep disturbances $(P<0.001)$, and dyspnoea and various psychosomatic symptoms $(P<$ $0.001)$. Nevertheless only $44 \%$ of the patients reported chest pain as the major disruptive symptom, whereas the remaining $56 \%$ reported uncertainty about the future, fear, or unspecified symptoms as being the most disturbing.

Conclusions-In a consecutive series of patients on the waiting list for possible coronary revascularisation, half the participants reported that uncertainty and fear were more disturbing than chest pain.
\end{abstract}

(Heart 1996;75:257-260)

Keywords: coronary revascularisation; ischaemic heart disease; chest pain; quality of life

The number of patients with symptomatic ischaemic heart diseases requiring evaluation for revascularisation has increased during the past two decades. Some of these patients can be maintained on anti-ischaemic treatment with nitrates, $\beta$ blockers, and calcium blockers with good pain control or relief. The major indication for coronary angiography and revascularisation is chest pain affecting the quality of life despite optimum medical treatment. ${ }^{1-4}$ In a subset of patients, especially those with more advanced coronary artery disease and depressed cardiac function, bypass surgery may improve survival. ${ }^{5-10}$ The effects on other aspects of the quality of life are less well documented. 1112

This study was undertaken to describe symptoms and complaints among patients referred for either coronary angiography or revascularisation, with the emphasis on the severity of pain and reduction of wellbeing; an additional aim was to evaluate the relation between pain and the other factors affecting wellbeing. We already knew that the patients had to wait a long time for revascularisation and that their relations with doctors and hospitals were often poor.

\section{Methods}

SUBJECTS

All the patients on three different waiting lists - coronary angiography, percutaneous transluminal coronary angioplasty (PTCA), and coronary artery bypass grafting (CABG) -in western Sweden in September 1990 were sent a questionnaire. In western Sweden, there are 17 major hospitals serving a total population of 1.6 million. At the time of the investigation, coronary angiography was performed at three of these hospitals, Sahlgrenska Hospital and Östra Hospital in Göteborg and Skövde Hospital in Skövde (in 1991 a total of 1487 procedures). CABG and PTCA were only performed at Sahlgrenska Hospital (695 and 402 procedures respectively in 1991).

\section{PROCEDURES}

During one week in September 1990, all the patients $(n=904)$ on the three different waiting lists for coronary angiography $(n=522)$, PTCA ( $n=57)$, or CABG $(n=325)$ were approached with a questionnaire. The patients were sent a reminder about the questionnaire after three weeks. The questionnaire was answered by 831 patients (92\%), $711(79 \%)$ of whom responded without having to be sent a reminder. This report deals with these 831 patients. About half of the questions were from the Nottingham health profile. ${ }^{13}$ The following issues were raised: whether the patients actually suffered from or had suffered from an acute myocardial infarction, angina pectoris, hypertension, diabetes mellitus; their present treatment; waiting time for a given procedure; present working situation; frequency of chest pain; intensity of pain on a scale of 0-10, where 0 represented no pain and 10 the most intensive pain the patient could imagine; dyspnoea and tachycardia; influence of symptoms on daily activities; nervous reactions in daily life and sleeping disorders; use of sedatives and sleeping pills; identify the most disturbing symptom.

The patients were divided into three differ- 
Table 1 Clinical history in relation to severity of pain

\begin{tabular}{|c|c|c|c|c|c|}
\hline & $\begin{array}{l}\text { All patients } \\
\text { on the } \\
\text { waiting list } \\
(n=831)\end{array}$ & $\begin{array}{l}\text { Pain } \\
\text { group I } \\
(n=249)\end{array}$ & $\begin{array}{l}\text { Pain } \\
\text { group II } \\
(n=289)\end{array}$ & $\begin{array}{l}\text { Pain } \\
\text { group III } \\
(n=270)\end{array}$ & $P^{*}$ \\
\hline $\begin{array}{l}\text { Age (years) } \\
\text { median }(25 \%-75 \% \\
\text { centiles) }\end{array}$ & $63(57-69)$ & $61(56-68)$ & $63(57-68)$ & $64(57-69)$ & \\
\hline Sex (female; \%) & 21 & 22 & 23 & 19 & \\
\hline $\begin{array}{l}\text { Clinical history of: (\%) } \\
\text { Angina pectoris } \\
\text { Myocardial infarction } \\
\text { Hypertension } \\
\text { Nervous disorders } \\
\text { Diabetes }\end{array}$ & $\begin{array}{l}89 \\
57 \\
46 \\
15 \\
11\end{array}$ & $\begin{array}{r}79 \\
57 \\
42 \\
13 \\
7\end{array}$ & $\begin{array}{l}93 \\
53 \\
44 \\
16 \\
12\end{array}$ & $\begin{array}{l}94 \\
61 \\
50 \\
16 \\
13\end{array}$ & $\begin{array}{l}<0.0001 \\
<0.05\end{array}$ \\
\hline $\begin{array}{l}\text { Medication: (\%) } \\
\text { Long and/or short } \\
\text { acting nitrates } \\
\beta \text { Blockers } \\
\text { Calcium antagonists } \\
\text { Diuretics for heart } \\
\text { failure } \\
\text { Sedatives (including } \\
\text { sleeping pills) } \\
\text { Two to three } \\
\text { anti-ischaemic } \\
\text { drugs used }\end{array}$ & $\begin{array}{l}72 \\
70 \\
47 \\
\\
26 \\
\\
12\end{array}$ & $\begin{array}{l}53 \\
69 \\
35 \\
23 \\
\\
10\end{array}$ & $\begin{array}{l}75 \\
69 \\
52 \\
21 \\
11\end{array}$ & $\begin{array}{l}85 \\
73 \\
53 \\
33 \\
\\
13\end{array}$ & $\begin{array}{l}<0.0001 \\
<0.0001 \\
<0.01\end{array}$ \\
\hline
\end{tabular}

${ }^{\star} P$ values refer to the correlation between severity of pain and baseline variables. †Short and long acting nitrates, $\beta$ blockers, and calcium antagonists.

Table 2 Chest pain limitation in daily activity

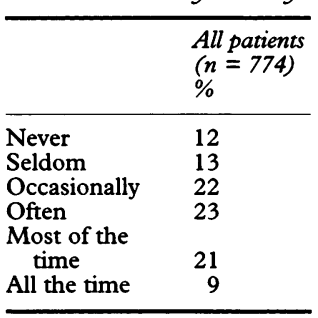

ent pain groups, mild (I), moderate (II), and severe (III) chest pain. The patients in pain group I $(n=249)$ had pain less than once a week and a maximum intensity of less than 5 . In pain group II $(n=289)$, the patients had one to six attacks per week with a pain intensity of $\geqslant 5$, or daily attacks with an intensity of 5-6. The patients in pain group III $(n=$ 270) had daily attacks with an intensity of $\geqslant 7$.
Table 3 The most disturbing symptoms

\begin{tabular}{lllll}
\hline & $\begin{array}{l}\text { Pain } \\
(\%)\end{array}$ & $\begin{array}{l}\text { Uncertainty } \\
(\%)\end{array}$ & $\begin{array}{l}\text { Fear } \\
(\%)\end{array}$ & $\begin{array}{l}\text { Unspecified } \\
\text { symptoms } \\
(\%)\end{array}$ \\
\hline All patients $(\mathrm{n}=786)$ & 44 & 43 & 6 & 7 \\
$<65$ years $(\mathrm{n}=444)$ & 35 & 48 & 7 & 10 \\
$\geqslant 65$ years $(\mathrm{n}=342)$ & 56 & 38 & 3 & 3 \\
Waiting time $\leqslant 6$ months & 44 & 44 & 6 & 6 \\
Waiting time $>6$ months & 43 & 44 & 6 & 8 \\
\hline
\end{tabular}

The differences between the age groups are significant $(P<0.001)$.

Table 4 Dyspnoea, psychosomatic and various psychological symptoms in relation to severity of pain. (Percentages refer to the occurrence of symptoms often, most of the time, or all the time)

\begin{tabular}{lllll}
\hline & $\begin{array}{l}\text { Pain } \\
\text { group } I \\
(n=249) \\
\%\end{array}$ & $\begin{array}{l}\text { Pain } \\
\text { group II } \\
(n=289) \\
\%\end{array}$ & $\begin{array}{l}\text { Pain } \\
\text { group III } \\
(n=270)\end{array}$ & $\begin{array}{l}\text { \% } \\
\%\end{array}$ \\
\hline Dyspnoea & 25 & 45 & 60 & $P^{*}$ \\
Dyspnoea on exertion & 50 & 73 & 81 & $<0.001$ \\
Palpitations & 10 & 16 & 30 & $<0.001$ \\
Tiredness & 44 & 62 & 77 & $<0.001$ \\
Weakness & 29 & 46 & 66 & $<0.001$ \\
Lack of energy & 24 & 37 & 53 & $<0.001$ \\
Headache & 5 & 12 & 18 & $<0.001$ \\
Dizziness & 5 & 10 & 11 & $<0.001$ \\
Stomach trouble & 10 & 10 & 18 & $<0.001$ \\
Sweating & 15 & 18 & 21 & $<0.001$ \\
Anxiety & 23 & 26 & 32 & $<0.001$ \\
Depression & 14 & 23 & 29 & $<0.001$ \\
Restlessness & 15 & 28 & 31 & $<0.001$ \\
Inability to act & 14 & 25 & 32 & $<0.001$ \\
Difficulty relaxing & 19 & 27 & 33 & $<0.001$ \\
Difficulty concentrating & 11 & 16 & 21 & $<0.001$ \\
Irritability & 21 & 35 & 38 & $<001$ \\
Indecision & 11 & 13 & 20 & $<001$ \\
Feeling of stress & 18 & 28 & 30 & 0.05 \\
Use of sedatives & 5 & 7 & 9 & \\
\hline
\end{tabular}

$\star P$ values refer to the correlation between severity of pain (scale 1-3) and the frequency of physical symptoms/emotional reactions (scale 1-6, never-seldom-occasionally-often-most of the time-all of the time).

\section{STATISTICS}

Pitman's non-parametric permutations test ${ }^{14}$ was used to test for correlations. The Edgeworth expansion ${ }^{15}$ was used to calculate $\mathrm{P}$ values. In table 3 , the $\chi^{2}$ was used to test for differences in proportions between age groups and between waiting time groups. All $P$ values are two sided and have not been corrected for multiple comparisons. $P$ values of $<0.05$ are given in the tables.

\section{Results}

RELATIONS BE'TWEEN SEVERITY OF PAIN AND CLINICAL HISTORY (table 1)

There was a significant correlation between the severity of pain and the presence of a history of angina pectoris and diabetes mellitus. As expected, severity of pain also correlated with $\beta$ blocker and calcium antagonist treatment and with diuretic treatment for heart failure.

In pain group I, 54 patients reported no pain at all. It was clear from the hospital records that they all had severe ischaemic heart disease with the exception of 11 patients with primary valve disease. Some of the patients in pain group I were immobilised or had to stay in hospital during the waiting period.

Seventy two per cent of the patients received optimum treatment in the form of two or three anti-ischaemic drugs (long and short acting nitrates, $\beta$ blockers, and calcium antagonists).

The median waiting time for coronary angiography, PTCA, and CABG was 8,5 , and 5 months, respectively.

\section{DAILY ACTIVITIES LIMITED BY CHEST PAIN}

Eighty eight per cent of the patients reported chest pain symptoms that limited their daily activities to a greater or lesser degree (from "seldom" to "all the time") (table 2). Of the patients who reported no chest pain limiting daily activity at all, two thirds had chest pain on other occasions not related to daily activity, and $78 \%$ of these had verified heart disease. The patients also reported pain in stress situations $(80 \%)$, when worried $(74 \%)$, and at night $(35 \%)$.

\section{THE MOST DISTURBING SYMPTOMS}

As can be seen from table $3,56 \%$ of all patients reported that uncertainty, fear, or other unspecified problems were the most disturbing symptoms, while pain was the worst for $44 \%$. The patients answered the question on uncertainty by giving explanations such as concern about the future and whether they would be treated in time, but they were also concerned about their financial situation and about the future of their families. Among patients under 65 years of age, only $35 \%$ reported that pain was the worst symptom, while $65 \%$ were more disturbed by uncertainty, fear, or unspecified symptoms. Forty four per cent of the patients with a waiting time shorter than six months reported pain as the most disturbing symptom, as did $43 \%$ of 
Table 5 Sleeping disorders in relation to severity of pain. (Percentages refer to the occurrence of symptoms most of the time or all of the time)

\begin{tabular}{|c|c|c|c|c|}
\hline & $\begin{array}{l}\text { Pain } \\
\text { group I } \\
(n=249) \%\end{array}$ & $\begin{array}{l}\text { Pain } \\
\text { group II } \\
(n=289) \%\end{array}$ & $\begin{array}{l}\text { Pain } \\
\text { group III } \\
(n=270) \%\end{array}$ & $P^{*}$ \\
\hline Restless sleep & 9 & 17 & 19 & $<0.001$ \\
\hline Unwanted sleeping periods & 6 & 9 & 9 & $<0.001$ \\
\hline Use of sleeping pills & 4 & 6 & 8 & $<0.01$ \\
\hline Difficulty going to sleep & 9 & 16 & 21 & $<0.001$ \\
\hline Difficulty waking up & 4 & 5 & 5 & $<0.05$ \\
\hline $\begin{array}{l}\text { Repeated awakening and } \\
\text { insomnia }\end{array}$ & 10 & 18 & 23 & $<0.001$ \\
\hline Snoring & 22 & 22 & 23 & \\
\hline Nightmares & 3 & 4 & 6 & $<0.001$ \\
\hline $\begin{array}{l}\text { Tiredness due to lack of } \\
\text { sleep }\end{array}$ & 16 & 21 & 29 & $<0.001$ \\
\hline Too early awakening & 11 & 19 & 21 & $<0.001$ \\
\hline
\end{tabular}

$\star P$ values refer to the correlation between severity of pain (scale 1-3) and the frequency of sleeping disorders (scale 1-5, never-seldom-occasionally-most of the time-all of the time).

the patients with a waiting time of more than six months.

SUBJECTIVE SYMPTOMS OTHER THAN PAIN IN RELATION TO SEVERITY OF CHEST PAIN

There was a significant correlation between severity of pain and the frequency of most of the other symptoms that were evaluated. As shown in table 4, all the dyspnoea, psychosomatic, and psychological symptoms listed in the tables were significantly associated with the severity of chest pain, that is, the more severe the chest pain, the higher the frequencies with which the symptoms were reported, or vice versa. Similarly, various aspects of sleep disturbance were strongly related to the severity of pain (table 5). All but one of the symptoms listed in tables 4 and 5 were significantly correlated with pain.

SLEEPING DISORDERS IN RELATION TO THE MOST DISTURBING SYMPTOM

Nineteen per cent of patients who reported pain as the most disturbing symptom reported difficulty going to sleep most of the time or all the time, as compared with $14 \%$ of patients who reported that nervous disorders were the most disturbing symptom (NS). The corresponding figures with regard to repeated awakening and insomnia were $21 \%$ and $16 \%$ respectively (NS).

\section{Discussion}

In this study we describe the severity of symptoms with particular emphasis on chest pain among patients on the waiting list for coronary angiography, PTCA, and CABG. The lack of facilities for evaluation and revascularisation has created problems for patients and the medical profession and has put a strain on the nation's resources. Revascularisation has been found to be highly effective in the relief of severe angina and a subset of patients may experience an improvement in survival. ${ }^{1-8}$ Despite the parallel introduction of potent medical treatments for angina pectoris comprising $\beta$ blockers, calcium antagonists, and long acting nitrates, referrals for evaluation for possible revascularisation have risen to a marked degree in all the developed countries.

As expected, most of the patients had a his- tory of angina pectoris (89\%). Myocardial infarction was seen in $57 \%$ of the patients. These figures, as well as the figures relating to hypertension and diabetes mellitus, are in agreement with earlier findings. ${ }^{6}$ Nervous disorders were reported in $15 \%$ of the patients on the waiting list.

Patients with more severe pain had a more frequent history of diabetes. This could be explained by more extensive coronary artery disease in these patients. However, previous reports indicate that, among patients with ischaemic heart disease, those with diabetes have fewer symptoms of pain. ${ }^{16} 17$

Another important observation was the correlation between severity of pain and medication for congestive heart failure. This raises the possibility of confounding factors such as dyspnoea when evaluating the relation between psychosomatic and sleep disorders and the severity of pain.

In the evaluation of symptoms other than pain we used questions from the Nottingham health profile. Various methods for evaluating wellbeing and quality of life have recently been criticised for inaccuracy. ${ }^{13}$ However, at present there is probably no better alternative.

The most disturbing problem for the majority of patients in the present study who had been on the waiting list for a fairly long time (median 5-8 months per procedure) was not the pain but other reactions such as fear and uncertainty about the future. It does not appear that a longer waiting time increases the uncertainty, fear, or other unspecified symptoms. Forty nine per cent of the patients listed uncertainty about the future or fear as the major problem, while only $44 \%$ reported chest pain as the dominant symptom.

We found that elderly patients reported pain as their most disturbing symptom more often than younger patients. Symptoms among patients with ischaemic heart disease have previously been related to age. ${ }^{18}$ Some symptoms like dyspnoea and fatigue have been reported to be more common among the elderly. ${ }^{18}$ This trend could be explained by a general tendency for older patients to suffer from such symptoms or by the fact that they more often develop congestive heart failure. ${ }^{19}$ Psychosomatic symptoms, on the other hand, have been reported more frequently by younger patients. ${ }^{18}$ These findings must be related to the fact that many of the patients still tried to work and were therefore exposed to more stressful situations. ${ }^{20}$ When it comes to the possibility of suffering a new myocardial infarction, the long waiting time probably increases the trauma among younger patients. The younger ones were worried about the future, about their families, and their economic situation. The finding that uncertainty about the future or fear were the major problems in such a large population of patients on the waiting list for eventual coronary revascularisation has not previously been reported. However, symptoms of anxiety, depression, and psychosomatic complaints in relation to heart disease have previously been described in other situations. ${ }^{21-23}$

It is possible to argue about the degree to 
which the nervous disorders reported by patients were related to the waiting period, and about the degree to which these disorders are common in all patients with coronary artery disease. The correlation between the degree of psychological symptoms and the severity of chest pain, and the apparent lack of dependence of the most disturbing symptom on the waiting period would indicate only a slight influence by the waiting period on psychological disorders and among these patients.

In the present study, there was a significant correlation between the severity of pain and the frequency with which sedatives and sleeping pills were used. This association has previously been reported in patients with angina pectoris, with or without a referral for revascularisation. ${ }^{24-26}$ However, even patients with less pain often reported various symptoms and sleep disturbances.

There is some uncertainty about cause and effect. As a result, we did not evaluate the extent to which reported pain may be influenced by anxiety and depression. Furthermore, all the data derive from patients' own reports and are likely to lead to high correlations because of a tendency for people in a neurotic state to report many symptoms and problems including pain, anxiety, and depression.

It can be concluded that in consecutive patients on the waiting list for possible coronary revascularisation there is a highly significant relation between the severity of chest pain and various aspects of wellbeing. However, half the patients reported that uncertainty and fear were more disturbing than chest pain, and a large proportion of patients, including those with less pain, reported various psychological and psychosomatic symptoms. It seems reasonable to recommend that doctors should pay more attention to their patients' fear and uncertainty about the future and not simply focus their interest on their chest pain.

This study was supported by grants from the Medical Faculty of the University of Göteborg and from Wilhelm and Martina Lundgren's Foundation.

1 Bengtson A, Herlitz J, Karlsson T, Hjalmarson $\AA$. The epidemiology of a coronary waiting list. A description of all the patients. F Intern Med 1994;235:263-9.

2 Bengtson A, Herlitz J, Karlsson T, Brandrup-Wognsen G Hjalmarson $\AA$. The appropriateness of performing coronary angiography and coronary artery revascularization in nary angiography and coronary artery revasculariz

3 Ross J, Brandenburg RO, Dinsmore RE, et al. Guidelines for coronary angiography. A report of the American College of Cardiology/American Heart Association Task
Force on Assessment of Diagnostic and Therapeutic Force on Assessment of Diagnostic and Therapeutic
Cardiovascular Procedures (subcommittee on Coronary Aardiovascular Procedures (subcommittee on Co

4 Bourassa MG, Alderman EL, Bertrand M, et al. Report of the Joint ISFC/WHO Task Force on Coronary Angioplasty. Circulation 1988;78:780-9.

5 European Coronary Surgery Study Group. Long-term results of prospective randomized study of coronary artery bypass surgery in stable angina pectoris. Lancet 1982;ii: $1173-80$.

6 Coronary Artery Surgery Study (CASS). A randomized trial of coronary artery bypass surgery. Survival data. Circulation 1983;68:939-50.

7 The Veterans Administration Coronary Artery Bypass Surgery Cooperative Study Group. Eleven-year survival in the Veterans Administration randomized trial of coronary bypass surgery for stable angina. $N$ Engl $f \mathrm{Med}$ nary bypass surge

8 Varnauskas E. Twelve-year survival in the randomized European coronary surgery study. $N$ Engl f Med 1988; 319:332-7.

9 Alderman EL, Bourassa MG, Cohen LS, et al. Ten-year follow-up of survival and myocardial infarction in the randomized Coronary Surgery Study. Circulation 1990; 82:1629-46.

10 Nwasokwa ON, Koss JH, Friedman GH, Grunwald AM, Bodenheimer MM. Bypass surgery for chronic stable angina: predictors of survival benefit and strategy for patient selection. Ann Intern Med 1991;114:1035-49.

11 Coronary artery surgery study (CASS). A randomized trial of coronary artery bypass surgery. Quality of life in patients randomly assigned to treatment groups. Circulation 1983;68:951-60.

12 Hoad NA, Crawford IC. Rehabilitation after coronary artery bypass grafting and improved quality of life. $\mathrm{Br} \mathcal{F}$ Sports Med 1990;24:120-2.

13 Gill TM, Feinstein AR. A critical appraisal of the quality of quality-of-life measurements. $¥ A M A$ 1994;272:619-26.

14 Bradley J. Distribution-free statistical tests. London: PrenticeHall, 1968:68-86.

15 Cramer H. Mathematical methods of statistics. Princeton: Princeton University Press, 1946:228-31.

16 Chipkin SR, Frid D, Alpert JS, Baker SP, Dalen JE, Aronin $\mathrm{N}$. Frequency of painless myocardial ischemia during exercise tolerance testing in patients with and without diabetes mellitus. Am $\mathcal{F}$ Cardiol 1987;59:61-5.

17 Niakan E, Harati Y, Rolak LA, Comstock JP, Rokey R. Silent myocardial infarction and diabetic cardiovascular autonomic neuropathy. Arch Intern Med 1986;146: 2229-30.

18 Wiklund I, Karlson BW, Bengtson A, Herlitz J. Subjective symptoms and well-being one year after acute myocardial infarction in relation to age. Cardiol Elderly 1993;1: 523-9.

19 Emanuelsson H, Karlson BW, Herlitz J. Characteristics and prognosis of patients with acute myocardial infarcand prognosis of patients with acute myocardial infarc-
tion in relation to occurrence of congestive heart failure. tion in relation to occurrence

20 Dellipiani AW, Cay EL, Philip AE, Vetter NJ, Colling WA, Donaldson RJ, et al. Anxiety after a heart attack. Br Heart

21 Haynes SG, Feinleib M, Kannel WB. The relationship of psychosocial factors to coronary heart disease in the Framingham study. 1. Methods and risk factors. $A m \mathcal{F}$ Epidemiol 1978;107:362-81.

22 Haynes SG, Feinleib M, Levine S, Scotch N, Kannel WB. The relationship of psychosocial factors to coronary heart disease in the Framingham study: 2 . Prevalence of coronary heart disease. Am ₹ Epidemiol 1978;107:384-402.

23 Haynes S, Feinleib M, Kannel W. The relationship of psychosocial factors to coronary heart disease in the Framingham Study: 3. Eight-year incidence of coronary heart disease. Am $₹$ Epidemiol 1980;111:37-58.

24 Mayou $R$. The patient with angina symptoms and disability. Postgrad Med F 1973;49:250-4.

25 Zaitzev VP. Psychological correlates of some cardiac pain syndromes of IHD. Acta Med Scand 1982;660(suppl): 95-102.

26 Reeves JT. Medical management of the patient with angina pectoris: an overview of the problem. Circulation 1982;65 (suppl 2):3-12. 